\title{
JOGO DE TABULEIRO FLORA DA CAATINGA: CONHECER PARA CONSERVAR
}

\author{
Mariana Nogueira Bezerra ${ }^{1}$ \\ Glaucia Suêrda Gomes do Nascimento ${ }^{2}$ \\ Nélia Rodrigues da Silva ${ }^{3}$ \\ Regina Lúcia Félix de Aguiar Lima ${ }^{4}$ \\ Elâine Maria dos Santos Ribeiro ${ }^{5}$
}

Resumo: $\mathrm{O}$ jogo didático é uma ferramenta de aprendizagem que desperta o conhecimento de forma prazerosa e divertida. O objetivo deste trabalho foi desenvolver um jogo didático para ampliar os conhecimentos sobre a flora da Caatinga e promover reflexões sobre sua conservação. Para desenvolvimento do jogo "Flora da Caatinga: conhecer para conservar", utilizou-se como modelo o Jogo da Vida® que é um jogo de tabuleiro da empresa Brinquedos Estrela $S . A \circledast$. O jogo desenvolvido apresenta abordagem contextualizada e atual das plantas da Caatinga, apresenta algumas relações das espécies com os seres humanos e aspectos relacionados à sustentabilidade, contribuindo para a aprendizagem, valorização e conservação sobre a biodiversidade da Caatinga.

Palavras-chave: Jogos Didáticos; Semiárido; Educação Ambiental; Metodologias Ativas.

Abstract: Didactic game is a learning tool that awakens knowledge in a pleasurable and fun way. The objective of this work was to develop a didactic game to expand the knowledge about Caatinga flora and to promote reflections on its conservation. To develop the game, entitled "Flora da Caatinga: know to conserve", the Jogo da Vida ${ }^{\circledR}$ board game by Brinquedos Estrela S.A® was used as a model. The game developed has a contextualized and current approach on the plants of the Caatinga, it presents some relations of the species with humans and aspects related to sustainability, contributing to the learning, valorization and conservation of the Caatinga.

Keywords: Educational Games; Semi-arid; Environmental education; Active Methodologies.

\footnotetext{
${ }^{1}$ Universidade de Pernambuco. E-mail:mariana.nogueira@upe.br. http://lattes.cnpq.br/4781460358806857

2Universidade de Pernambuco. E-mail: glaucia.suerda@upe.br. http://lattes.cnpq.br/8098969063041386

3 Universidade de Pernambuco. E-mail: nelia.rodrigues@upe.br. http://lattes.cnpq.br/3878666774688437

${ }^{4}$ Universidade de Pernambuco. E-mail: regina.aguiar@upe.br. http://lattes.cnpq.br/8549101690272163

${ }^{5}$ Universidade de Pernambuco. E-mail: elaine.ribeiro@upe.br. http://lattes.cnpq.br/3304685448889789

Revbea, São Paulo, V. 15, No 6: 52-78, 2020.
} 


\section{Introdução}

O uso dos recursos naturais é presente em todos os ecossistemas, como consequência do desenvolvimento humano; no entanto, se esse uso ocorre de forma desordenada ameaça os ecossistemas e pode causar problemas ambientais, como, por exemplo, a erosão e degradação do solo, aquecimento global, perda da biodiversidade e a contaminação dos recursos hídricos (WWF, 2020). No Brasil, soma-se a esses problemas a destinação inadequada dos resíduos sólidos, a exclusão social e elevado nível de pobreza (REIS; MARQUES, 2018). Enfrentar de forma efetiva esse quadro configura-se como um grande desafio para a construção de um Brasil sustentável, tendo por base os objetivos para o desenvolvimento sustentável, definidos globalmente (ONU, 2020). Deve-se, portanto, buscar as estratégias de enfrentamento desses problemas que envolvam uma articulação coordenada entre todos os tipos de intervenção ambiental direta, incluindo, neste contexto, a Educação Ambiental (EA) como um caminho que permite refletir e incentivar ações na busca de solução para esses problemas. Assim, todos os cidadãos devem ser sensibilizados para que ocorra uma transformação social em relação às questões ambientais (QUINTAS et al. 2006). Logo, o âmbito escolar é fundamental para o desenvolvimento da capacidade de refletir sobre os problemas ambientais, tendo em vista que é na escola onde os indivíduos constroem competências e valores, além de adquirir conhecimentos relacionados ao meio ambiente e à sociedade.

A EA se insere na sociedade como uma ferramenta para alcançar avanços na qualidade de vida e na promoção da sustentabilidade, na medida em que busca a valorização dos recursos naturais (ALVES et al. 2012). A evolução da consciência ambiental ocorre através do desenvolvimento de conhecimentos e habilidades que podem ser estimuladas por diversas ferramentas de aprendizado, como os jogos didáticos. Eles funcionam como um método divertido no processo de estudos escolares (FORTUNA, 2003; MENEZES, 2012), incentivando atitudes ambientalmente mais assertivas e promovendo conhecimentos sobre as questões ambientais. Através da sua aplicabilidade lúdica, que utiliza uma abordagem recreativa, os jogos didáticos alcançam o objetivo da aprendizagem, agregando conhecimentos aos educandos (GODOY; OLIVEIRA; CODOGNOTO, 2010).

Trabalhar os problemas ambientais no ambiente escolar é, no entanto, desafiador, especialmente quando tratamos de ecossistemas como a Caatinga, onde os recursos naturais são bastante utilizados, e foi historicamente negligenciada em termos de investimentos em pesquisa científica, possuindo ainda as escolas de ensino básico consideradas como as mais precarizadas (SANTOS et al. 2011; TRIGUEIRO, 2017). Uma prova que muito ainda se deve investir para a EA focada na valorização da Caatinga é quando encontramos notícias de especialistas de educação que discutem esse tema, como a divulgada por Trigueiro (2017).

Imagine o cenário em que uma criança de uma pequena escola na Caatinga Pernambucana decora detalhes sobre a geografia do sudeste asiático

revista brasileira educação ambiental 
ou mesmo as características da tundra subártica. Ao mesmo tempo, ignora as peculiaridades do bioma à sua volta (TRIGUEIRO, 2017).

Nesse contexto, o objetivo deste estudo foi desenvolver um jogo de tabuleiro no formato de trilha, para ampliar os conhecimentos sobre a flora da Caatinga e promover reflexões sobre sua conservação, que seja uma ferramenta de aprendizagem para alunos do Ensino Fundamental II, e que contribua para 0 desenvolvimento de competências $e$ habilidades relacionadas ao entendimento da flora da Caatinga, suas características e conservação. Tais habilidades estão relacionadas aos temas vida e evolução dos anos finais do ensino fundamental abordados na Base Nacional Comum Curricular (BRASIL, 2018). O jogo de tabuleiro denominado "Flora da Caatinga: conhecer para preservar" poderá ser utilizado como material didático nas aulas de Ciências em escolas que oferecem o Ensino Fundamental II. A sua utilização permite caracterizar a flora da Caatinga, abordando as espécies vegetais e seus mecanismos fisiológicos e adaptativos às condições ambientais, bem como busca estimular a sua conservação através do estímulo à reflexão, prática de ações sustentáveis, incentivo a novos hábitos e atitudes relacionados ao meio ambiente.

\section{Educação ambiental no ambiente escolar}

Através das gerações têm sido transmitidos os conhecimentos relativos aos cuidados necessários com a preservação do meio ambiente e, assim, disseminaram-se as práticas de conservação (SOUZA, 2011). Nos tempos atuais, a demanda por recursos naturais é bastante elevada, e muitas vezes, esse uso é insustentável, o que tem gerado cenários de crise ambiental que revelam a urgência na busca por formas de proteção (ZUPELARI; WICK, 2015). Ainda na década de 70 , do século passado, na Conferência de Estocolmo em 1972, a Educação Ambiental é proposta como campo da ação pedagógica para colaborar na minimização dos problemas ambientais e colocálos na pauta das discussões internacionais (MEDINA 2008). Práticas de EA aliadas a políticas públicas fundamentadas por legislações voltadas à prevenção e reparação dos altos indicadores de impactos ambientais podem favorecer as mudanças necessárias nos padrões e valores da sociedade, com vistas a mudanças de paradigmas em direção à sustentabilidade. A EA se insere como um elo de integração de todos os setores em prol da conservação dos recursos naturais. Mediante a conexão entre a teoria e ações locais contextualizadas, são criadas relações de cooperação onde é possível desenvolver saberes ambientais que se disseminam nos indivíduos e nas comunidades através de atitudes proativas em defesa do meio ambiente (ARDOIN; BOWERS, 2020).

Conforme a Política Nacional de Educação Ambiental (Lei $\mathrm{n}^{\circ}$ 9.795/1999), a EA é definida como "processos por meio dos quais o indivíduo e a coletividade constroem valores sociais, conhecimentos, habilidades, atitudes e competências voltadas para a conservação do meio ambiente, bem de uso 
comum do povo, essencial à sadia qualidade de vida e sua sustentabilidade". Ela constitui-se direito de todos os cidadãos brasileiros e deve ser desenvolvida em todas as modalidades de ensino (BRASIL, 1999; GARCIA et al. 2020).

A EA é primordial em todas as fases da vida e em todos os níveis educacionais, no ensino formal e não formal (UNESCO, 1978, LEAL FILHO; MIFSUD; PACE, 2018;). Contudo, é sabido pelo meio profissional de EA, que a infância é o período de maior avanço no aprendizado da temática ambiental (North American Association for Environmental Education [NAAEE, 2016; SAMUELSSON; KAGA, 2008; WILSON, 1996). Através de experiências ambientais vividas na infância, as crianças criam perspectivas positivas relacionadas ao meio ambiente que favorecem o desenvolvimento de uma consciência voltada à valorização dos recursos naturais (CAGLE, 2018; CHAWLA, 2007; 2009; JAMES, BIXLER; VADALA, 2010; ROSA, PROFICE; COLLADO, 2018; WELLS; LEKIES, 2006).

Segundo Lucchese e Alves (2013), a EA é o âmbito próprio para o desenvolvimento da temática meio ambiente no contexto escolar, tendo em vista esse ser um tema transversal preconizado nos Parâmetros Curriculares Nacionais (PCN). Os temas transversais são importantes para a construção de valores do educando, pois eles são debatidos de forma integrada com as problemáticas sociais, em que o tema meio ambiente tem a função de contribuir para a formação de pessoas conscientes, aptas a decidir e a atuar na realidade socioambiental, de modo comprometido com a vida, com o bem-estar de cada um e com o da sociedade, local e global (BRASIL, 1998).

Nessa perspectiva, a escola é de suma importância, tendo em vista que ela tem papel privilegiado no debate das questões ambientais, bem como na promoção do ensino-aprendizagem acerca da sociedade, ética, moral e da sensibilização ambiental (MACHADO; ABÍLIO, 2015). Além disso, a escola deve implementar metodologias para que o estudante aprenda sobre 0 ambiente em que vive, de modo que o ensino seja contextualizado e 0 educando possa aplicar o conhecimento para solucionar problemas de seu cotidiano, inclusive relacionados à sustentabilidade. Tais aspectos são enfatizados pela Base Nacional Comum Curricular- BNCC (BRASIL, 2018). Nesse sentido, os jogos didáticos são considerados um ótimo recurso didático para propor a contextualização do ensino, além de promover desenvolvimento cognitivo e social no aluno (GONZAGA et al. 2017).

\section{A flora da Caatinga: uma breve contextualização}

A vegetação predominante na região semiárida é tradicionalmente denominada de "Caatinga". Esse termo foi dado pelos povos nativos da região, de origem indígena, significando mata branca (caa = mata; tinga = branca e aberta) na língua tupi-guarani (TABARELLI et al. 2018). A Caatinga apresenta vegetação predominantemente xerófila, decídua, que permanece verde durante a estação das chuvas e perde suas folhas à medida que se acentua o período de estiagem (BAKKE et al. 2010). Devido à estiagem, as 
plantas são adaptadas ao estresse hídrico e térmico, desenvolvendo mecanismos para economia no uso da água (SENA, 2011). A disponibilidade de água é um fator limitante ao desenvolvimento das plantas da Caatinga, as quais, geralmente, apresentam folhas pequenas, espinhos, possuem hábito suculento, e o surgimento de folhas e flores ocorre em sincronia após ocorrer a precipitação (FERNANDES; QUEIROZ, 2018).

Espacialmente, a Caatinga cobre uma área de aproximadamente $912.529 \mathrm{~km}^{2}$, localizada na região Nordeste do país. Caracteriza-se pela vegetação arbórea-arbustiva, possui extensas superfícies planas com altitude variando de 300 a $500 \mathrm{~m}$, com precipitação anual variando entre 400 e 1200 $\mathrm{mm}$, e temperaturas médias de 25 a $30^{\circ} \mathrm{C}$ (TABARELLI et al. 2018; CORREIA et al. 2011). Sua ocorrência se dá nos estados do Piauí, Ceará, Rio Grande do Norte, Paraíba, Pernambuco, Alagoas, Sergipe, Bahia, a parte nordeste de Minas Gerais, no vale do Jequitinhonha e no Maranhão (LEAL et al. 2005; CORREIA et al. 2011).

A vegetação da Caatinga faz parte do bioma global Florestas e Arbustais Tropicais Sazonalmente Secos - FATSS, sendo um dos núcleos de FATSS que possuem maior riqueza e endemismos em todo o Mundo, apresentando cerca de $23 \%$ de espécies endêmicas, incluindo a ocorrência de 29 gêneros endêmicos, que tendem a ser raros e com distribuição restrita (FERNANDES; QUEIROZ, 2018). São exemplos de espécies vegetais endêmicas da Caatinga, carnaúba (Copernicia prunifera (Mill.), catingueira (Cenostigma pyramidale (Tul.) Gagnon \& G.P.Lewis), juazeiro (Ziziphus joazeiro Mart.), xique-xique (Pilosocereus gounellei (Weber)), mandacaru (Cereus jamacaru P. DC.), e jurema preta (Mimosa tenuiflora (Willd.) Poir.) (GIULIETTI et al. 2002).

$\mathrm{Na}$ Caatinga, ocorrem cerca de 3.150 espécies de angiospermas, pertencentes a 950 gêneros e 152 famílias, com grande diversidade das famílias Fabaceae, Euphorbiaceae, Asteraceae, Rubiaceae e Malvaceae, as quais se destacam pela sua ampla gama forma de crescimento e capacidade de ocupar nichos diferentes (FERNANDES; CARDOSO; QUEIROZ, 2020; QUEIROZ et al. 2017). As principais famílias da Caatinga em relação ao número de espécies, são: Leguminosae (278 espécies), Convolvulaceae (103 espécies), Malpighiaceae (71 espécies), Poaceae (66 espécies) e Cactaceae (57 espécies) (GIULIETTI; CONCEIÇÃO; QUEIROZ, 2006). Essa expressiva biodiversidade vegetal possibilita diversos usos das espécies vegetais da Caatinga pelo homem. As plantas da Caatinga apresentam grande potencial medicinal, e suas partes têm sido muito utilizadas pela população para cura de enfermidades (SILVA et al. 2015). Constituem fonte de renda para muitas famílias, que também a utilizam para confecção de objetos artesanais e extração de seus recursos não madeireiros. Ademais, muitas espécies apresentam madeira densa, com valor econômico e que são muito exploradas, o que tem resultado na degradação da Caatinga pela sua retirada e na ameaça de extinção dessas espécies (GARIGLIO et al. 2010). 
A Caatinga é um dos ecossistemas mais ameaçados do mundo, com altos índices de espécies ameaçadas de extinção, em razão das inúmeras ameaças antrópicas, como o desmatamento para implantação da agricultura e pasto, e as alterações em função das mudanças climáticas (MILES et al. 2006). Além disso, a Caatinga foi por bastante tempo negligenciada pela comunidade científica, que priorizaram estudos de outras regiões (SANTOS et al. 2011). Esse desinteresse da comunidade científica no passado pode ser entendido pela ideia errada de pobreza em diversidade de espécies e endemismo atribuído à Caatinga (ANDRADE-LIMA, 1981; GUSMÂO et al. 2016), o que a tornou a floresta brasileira menos conhecida e, em consequência, mais ameaçada (MORO et al. 2015). Diante do cenário de ameaça da Caatinga e de falta de ações efetivas de conservação, é imperativo a adoção de estratégias de conservação que utilizem a EA como ferramenta para enfrentar os problemas ambientais.

\section{Metodologia}

A primeira etapa do processo de criação do jogo foi baseada no Jogo da Vida®, um jogo de tabuleiro da empresa Brinquedos Estrela S.A. ® muito difundido entre o público infantil por ser um jogo dinâmico e envolvente. $O$ objetivo do jogo é que o participante se torne um magnata milionário. A partir desse princípio, foi definido que o jogo seria um tabuleiro de mesa, dinâmico, que teria um objetivo principal que envolvesse as crianças.

Após definir-se a ideia inicial, o primeiro passo foi a construção de um esboço com a possibilidade de o jogo ser desenvolvido em escala maior que 0 tabuleiro de mesa, uma escala real ou "gigante", na qual os alunos são os pinos do jogo. Dessa forma, fica a critério de quem for aplicar o jogo, confeccioná-lo na escala que melhor se adaptar à atividade desenvolvida.

Assim, trabalhou-se para criar o jogo sobre a flora da Caatinga, com uma trilha, que evolui de paisagens de degradação, áreas desmatadas e incêndios para uma paisagem de área conservada, com inúmeras espécies nativas. Além disso, também foram inseridas cartas com perguntas e respostas, em que os alunos devem usar os conhecimentos prévios obtidos em aula para fixar e aprofundar os conhecimentos sobre a flora. Para inserir conceitos de degradação ambiental, uso do fogo, desmatamento ilegal, recuperação de áreas degradas, resíduos sólidos e conservação, foram construídas "casas surpresas" no decorrer da trilha, com o intuito de dinamizar o jogo.

Para envolver os alunos no contexto ambiental, cada participante se torna um ativista ambiental famoso. Foram selecionados para inclusão no jogo os ativistas Maria do Socorro; Greta Thumberg; Jack Johnson; e Leonardo Di Caprio. Assim, de posse dos ativistas, cada jogador vai percorrer uma trilha na Caatinga, a qual se inicia em um cenário de degradação ambiental e, ao longo do caminho, segue um cenário de recuperação e conservação de áreas desse ecossistema.

revista brasileira educação ambiental 
O esboço inicial foi feito a mão livre e, posteriormente, toda a diagramação foi confeccionada no software CorelDRAW Graphics Suite 2020, versão gratuita de avaliação. Para as ilustrações contidas nas cartas de perguntas, carta bônus e quebra-cabeça, foram usadas imagens autorais, como também nas imagens utilizadas no tabuleiro, com exceção das figuras usadas para representar os incêndios e os ativistas ambientais. Essas foram obtidas através do Google imagens (Licenças Creative Commons).

A escolha das espécies foi feita por meio de uma seleção de espécies nativas da flora do ecossistema, utilizando como critério espécies que ocorrem amplamente no domínio fitogeográfico da Caatinga, conforme Moro et al. (2014), os quais catalogaram essas espécies a partir da compilação de 131 artigos de levantamentos florísticos e fitossociológicos feitos na Caatinga. A finalidade foi facilitar a assimilação dos nomes populares e científicos de forma mais branda, visto que o jogo deverá ser aplicado para crianças. Os nomes científicos das espécies que compõem o jogo foram conferidos no site Flora do Brasil 2020 (Tabela 1).

Ademais, o jogo foi projetado para ser aplicado com crianças na faixa etária média que varia dos 10 aos 15 anos de idade, estudantes do Ensino Fundamental II. Para a sua aplicação, recomenda-se que haja uma aula prévia onde o tema flora da Caatinga deve ser contextualizado. O nível de dificuldade do jogo também é adaptável para que o professor possa adequá-lo aos alunos envolvidos de acordo com o assunto abordado em aula e a faixa etária da turma.

Para a elaboração das perguntas do jogo foi utilizada a cartilha Conheça e conserve a Caatinga - O bioma Caatinga, volume 01 (Sena 2011), que aborda as principais características da Caatinga e das espécies que compõem sua vegetação. As perguntas são de diversos tipos e podem ter diferentes tipos de respostas: há perguntas objetivas, com quatro opções de respostas para selecionar ou com resposta do tipo verdadeiro ou falso; e há perguntas com respostas discursivas, nas quais o aluno deve explanar sobre uma característica da Caatinga ou responder a qual planta se refere a descrição contida na carta.

O jogo de tabuleiro Flora da Caatinga: Conhecer para conservar, aqui apresentado, faz parte da proposta "Aprendendo sobre 0 valor da biodiversidade da Caatinga e seus serviços ecossistêmicos no ensino escolar" apoiada pela Fundação de Amparo à Ciência e Tecnologia do Estado de Pernambuco (APQ - 0177-2.05/18). A construção desse jogo foi pensada para que o mesmo sirva como ferramenta para a valorização e aprendizagem da Caatinga no ensino básico; contudo, não foi possível testar a sua efetividade devido a pandemia causada pela COVID-19. 
Tabela 1: Lista de espécies de plantas da Caatinga selecionadas para uso no jogo

\begin{tabular}{|c|c|}
\hline Nome Popular & Nome Científico \\
\hline Umbuzeiro & Spondias tuberosa Arruda \\
\hline Aroeira & Myracrodruon urundeuva M. Allemao \\
\hline Mandacaru & Cereus jamacaru. DC. \\
\hline Xique-xique & Pilosocereus gounellei (A. Weber ex K. Schum.) Bly. ex. Rowl \\
\hline Facheiro & Pilosocereus pachycladus (F.Ritter) \\
\hline Coroa de frade & Melocactus sp. \\
\hline Quipá & Tacinga inamoena (K.Schum.) N.P.Taylor \& Stuppy \\
\hline Barriguda & Ceiba glaziovii K. Schum \\
\hline Juazeiro & Ziziphus joazeiro Mart. \\
\hline Baraúna & Schinopsis brasiliensis Engl. \\
\hline Ipê amarelo & Handroanthus shongiosus (Rizzini) S. Grose \\
\hline Umburana de cheiro & Amburana cearensis (Allemão) A.C. Sm. \\
\hline Umburana de cambão & Commiphora leptophloeos (Mart.) J. B. Gillet \\
\hline Carnaúba & Copernicia prunifera (Miller) H.E. Moore \\
\hline Ingazeiro & Inga sp. \\
\hline Quixabeira & Sideroxylon obtusifolium (Roem. \& Schult.) T.D. Penn. \\
\hline Pau ferro & Caesalpinia ferrea var. leiostachya Martius \\
\hline Caroá & Neoglaziovia variegata (Arruda) Mez \\
\hline Craibeira & Tabebuia aurea (Silva Manso) S. Moore \\
\hline
\end{tabular}

Fonte: Autoria própria.

Revbea, São Paulo, V. 15, № 6: 52-78, 2020. 


\section{Resultados e discussão}

\section{Desenvolvimento do jogo Flora da Caatinga: conhecer para conservar}

O jogo "Flora da Caatinga: Conhecer para conservar" foi elaborado de forma direcionada para turmas do Ensino Fundamental II; no entanto, pode ser utilizado em outras séries, bem como ser como atividade de EA em espaços não formais. Para adequar as necessidades específicas de cada série, idade dos alunos e assuntos abordados em sala de aula, o nível de dificuldade pode ser adaptado pelo professor por meio da seleção das diferentes cartas presentes no jogo.

O jogo desenvolvido é composto por tabuleiro (Figura 1); 12 cartas bônus (Figura 2); conjunto de 32 cartas com perguntas (Figura 3); 4 cartas dos ativistas ambientais (Figura 4); quebra-cabeça com a mesma imagem da última casa do tabuleiro, representando a Caatinga Conservada (Figura 5), que deve utilizado como premiação para o (s) vencedor (es). O verso das cartas do jogo está apresentado na Figura 2, juntamente com a carta bônus.

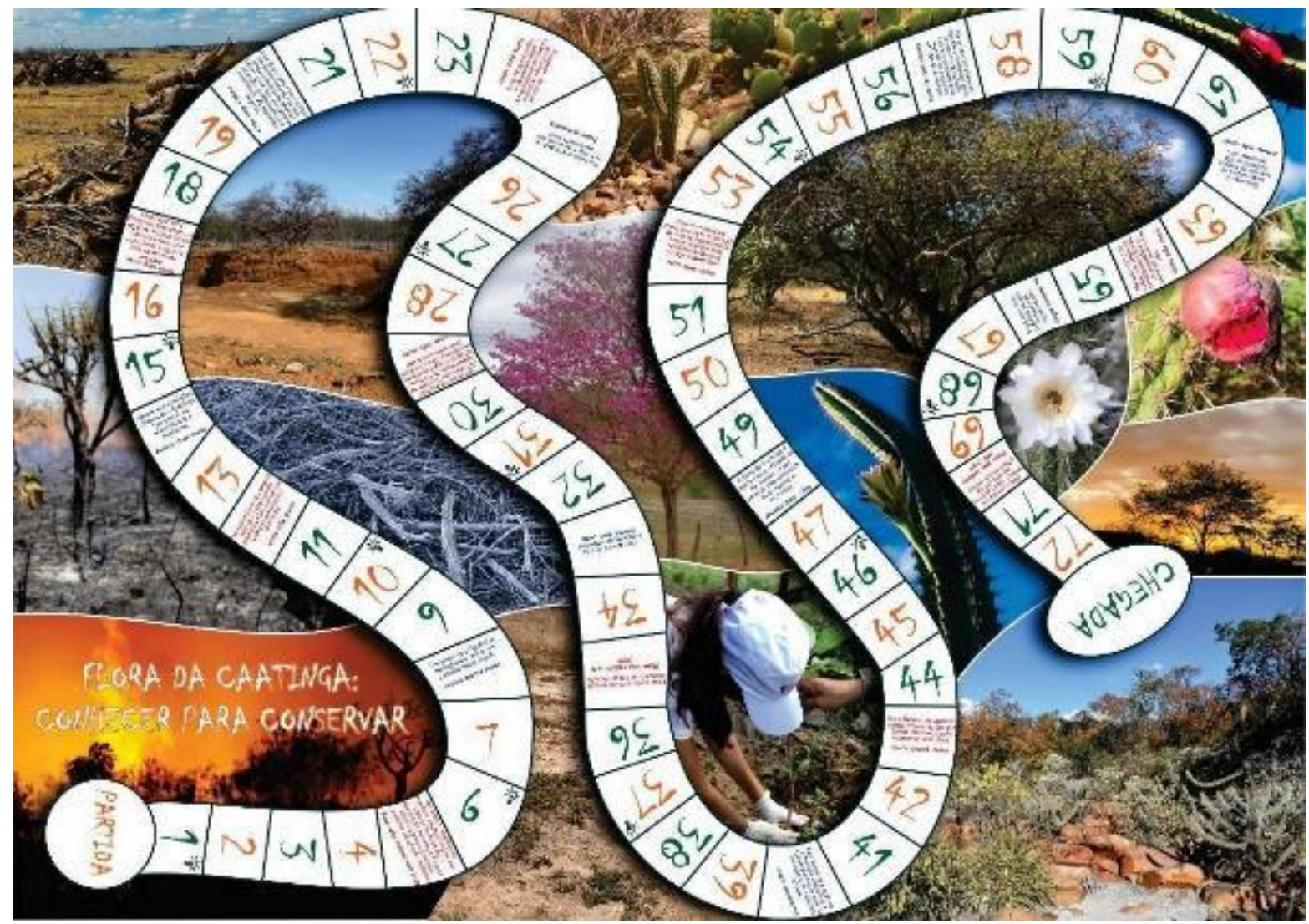

Figura 1: Tabuleiro do jogo Flora da Caatinga: Conhecer para conservar.

Fonte: Autoria própria.

revista brasileira

educação ambiental

O tabuleiro traz diversas informações sobre espécies, fisiologia, habitat, adaptações naturais, questões de degradação e sustentabilidade, que são introduzidas de forma sútil e contextualizada. Ele tem formato de trilha, com pontos de início (Partida) e de fim (Chegada). A trilha se inicia em uma área de Revbea, São Paulo, V. 15, № 6: 52-78, 2020. 
Caatinga com aspecto bastante degradado e pouca vegetação. Ao final, o jogo encerra em uma área de Caatinga preservada, que objetiva demonstrar aos alunos que, à medida que aprofundam os conhecimentos sobre a flora, aumenta também a sustentabilidade e conservação que 0 impacto das suas ações pode beneficiar o meio ambiente e o ecossistema como um todo.

O tabuleiro do jogo poderá ser confeccionado em diferentes dimensões e materiais. A confecção do tabuleiro pode ser feita escala real ou gigante, nesse caso recomenda-se que a impressão seja realizada em uma lona de 5,0 metros quadrados. Caso a escolha seja tabuleiro de mesa, sugere-se a confecção em papel panamá tamanho A2 $(42 \times 59,4 \mathrm{~cm})$ adesivado. As cartas podem ser produzidas em material resistente variável, com dimensões de $10 \mathrm{x}$ $7 \mathrm{~cm}$. O quebra-cabeça pode ser confeccionado em papel panamá, tamanho A3 $(29,7 \times 42 \mathrm{~cm})$, adesivado e cortado a laser.
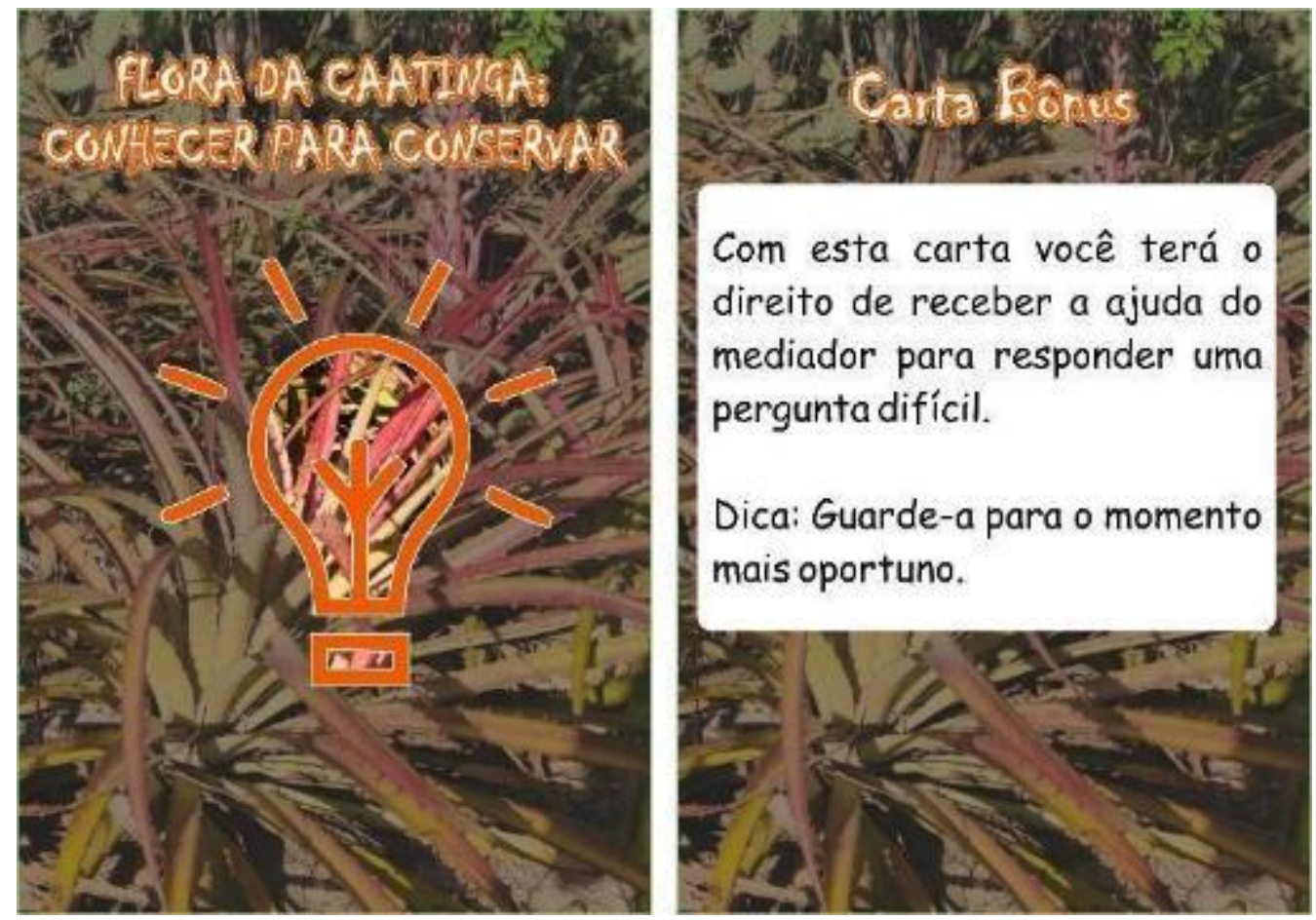

Figura 2: Cartas do jogo Flora da Caatinga: Conhecer para conservar, verso da carta e frente da carta bônus. Fonte: Autoria própria.

A trilha oferece informações sobre a flora da Caatinga, as principais espécies presentes e seus benefícios para o ser humano, assim como sobre as questões ambientais atreladas ao uso indiscriminado desse ecossistema, como a degradação, desmatamento ilegal, manejo da flora, desertificação, dentre outros. As informações são disponibilizadas de forma direta no tabuleiro, como também em forma de perguntas contidas nas cartas, que abrangem: charadas; perguntas de múltipla escolha e perguntas abertas. 

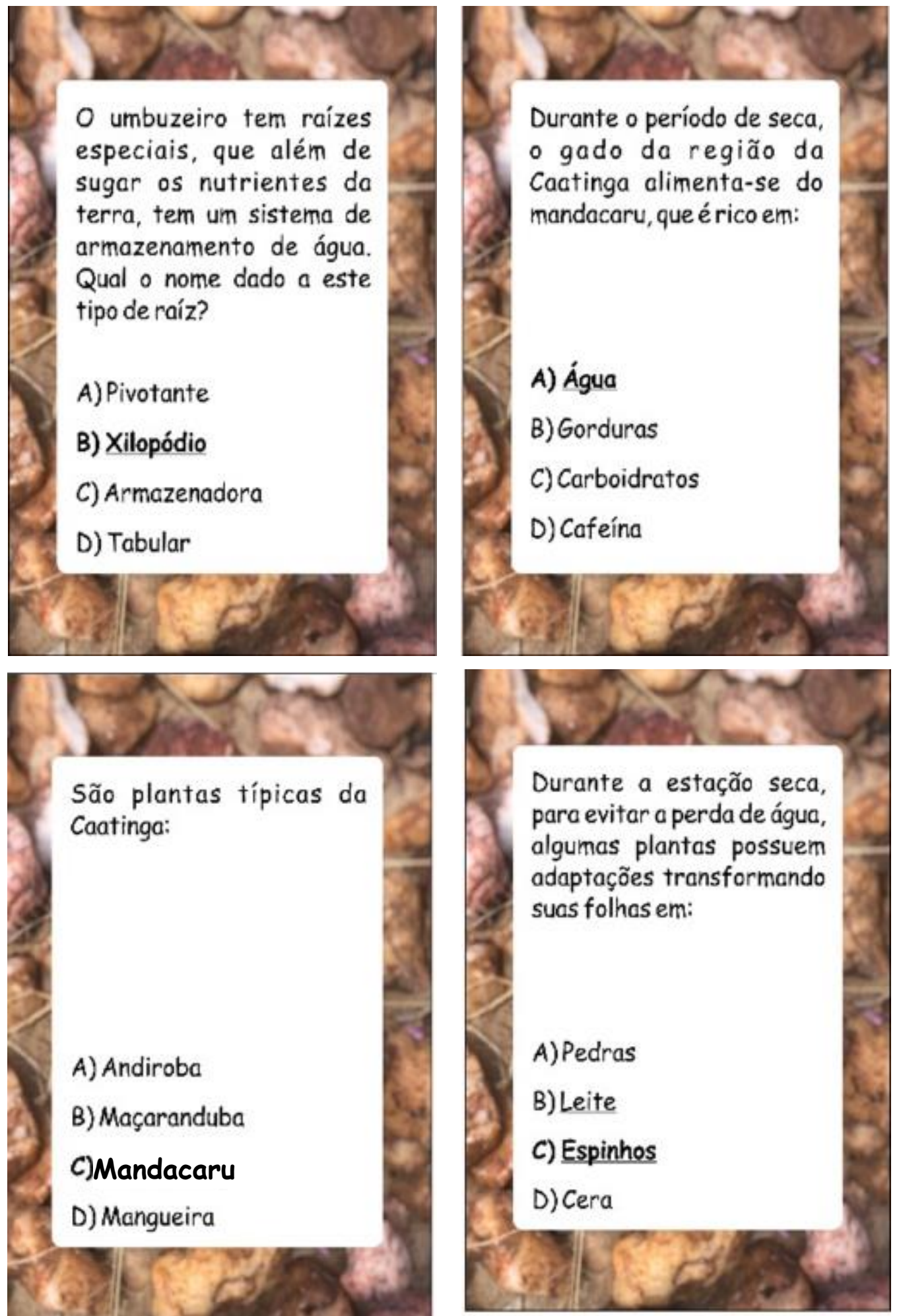

Figura 3: Cartas com perguntas do jogo Flora da Caatinga: conhecer para conservar. Fonte: autoria própria. 

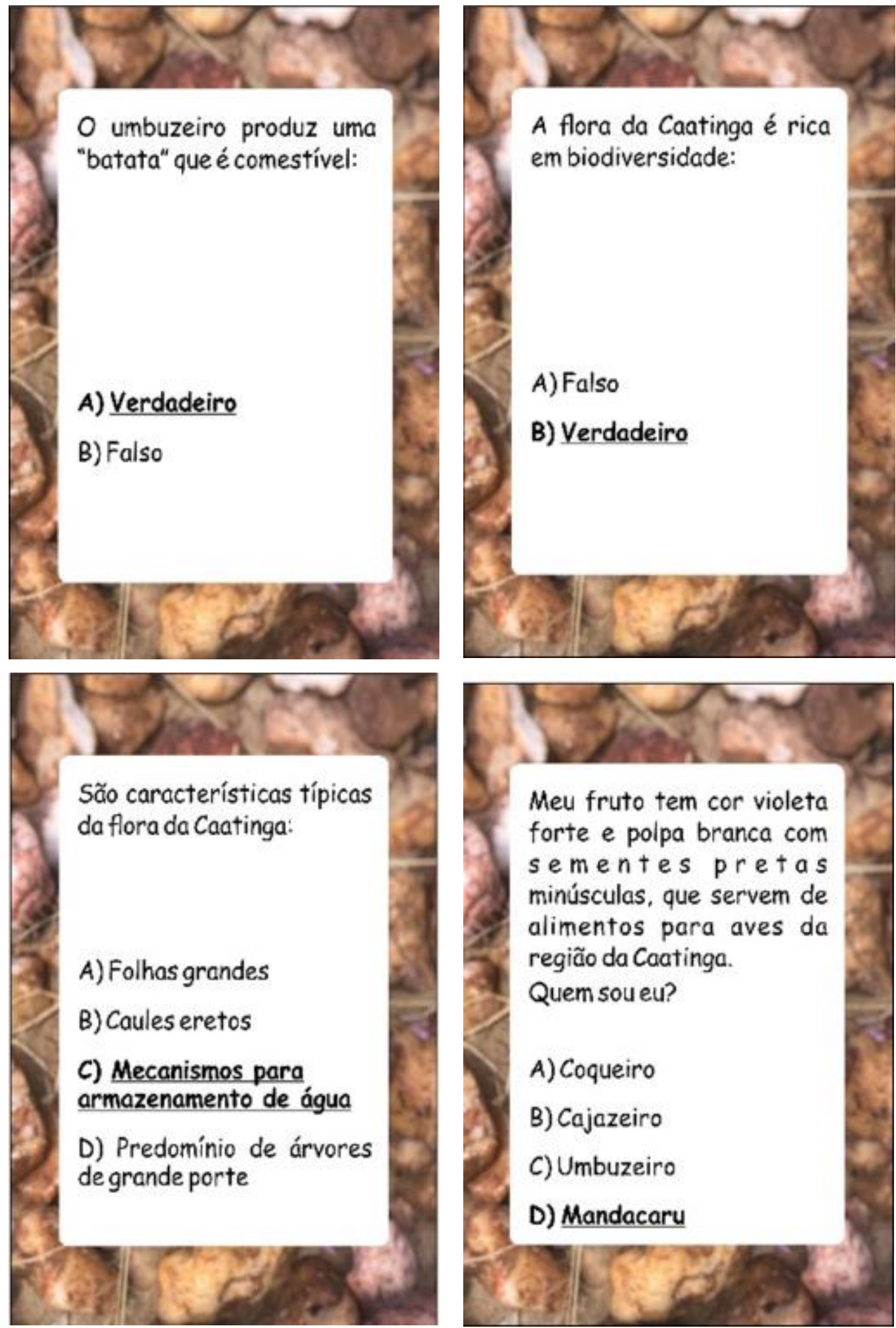

Figura 3: Cartas com perguntas do jogo Flora da Caatinga: conhecer para conservar (Continuação).

Fonte: autoria própria. 

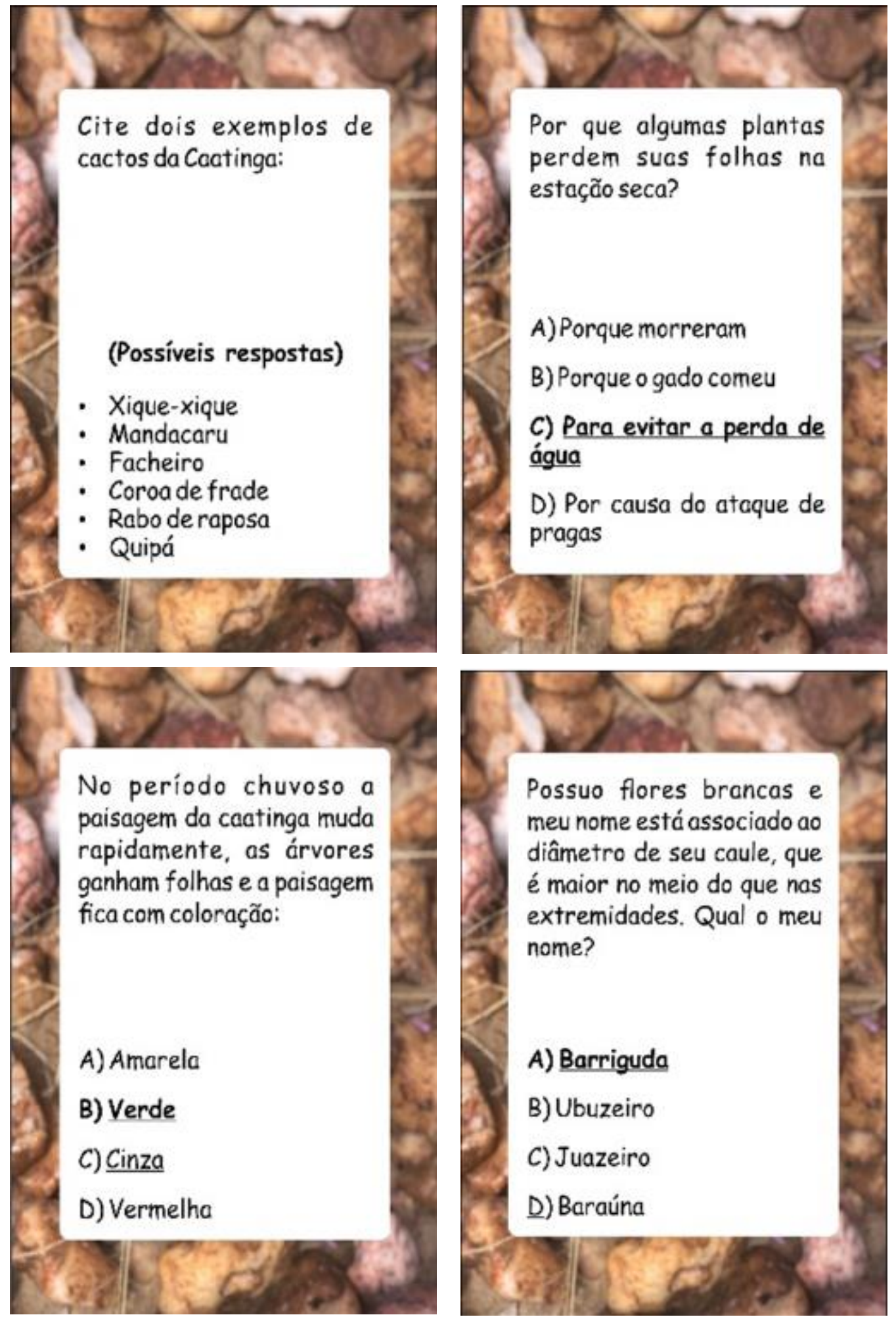

Figura 3: Cartas com perguntas do jogo Flora da Caatinga: conhecer para conservar (Continuação).

Fonte: autoria própria. 

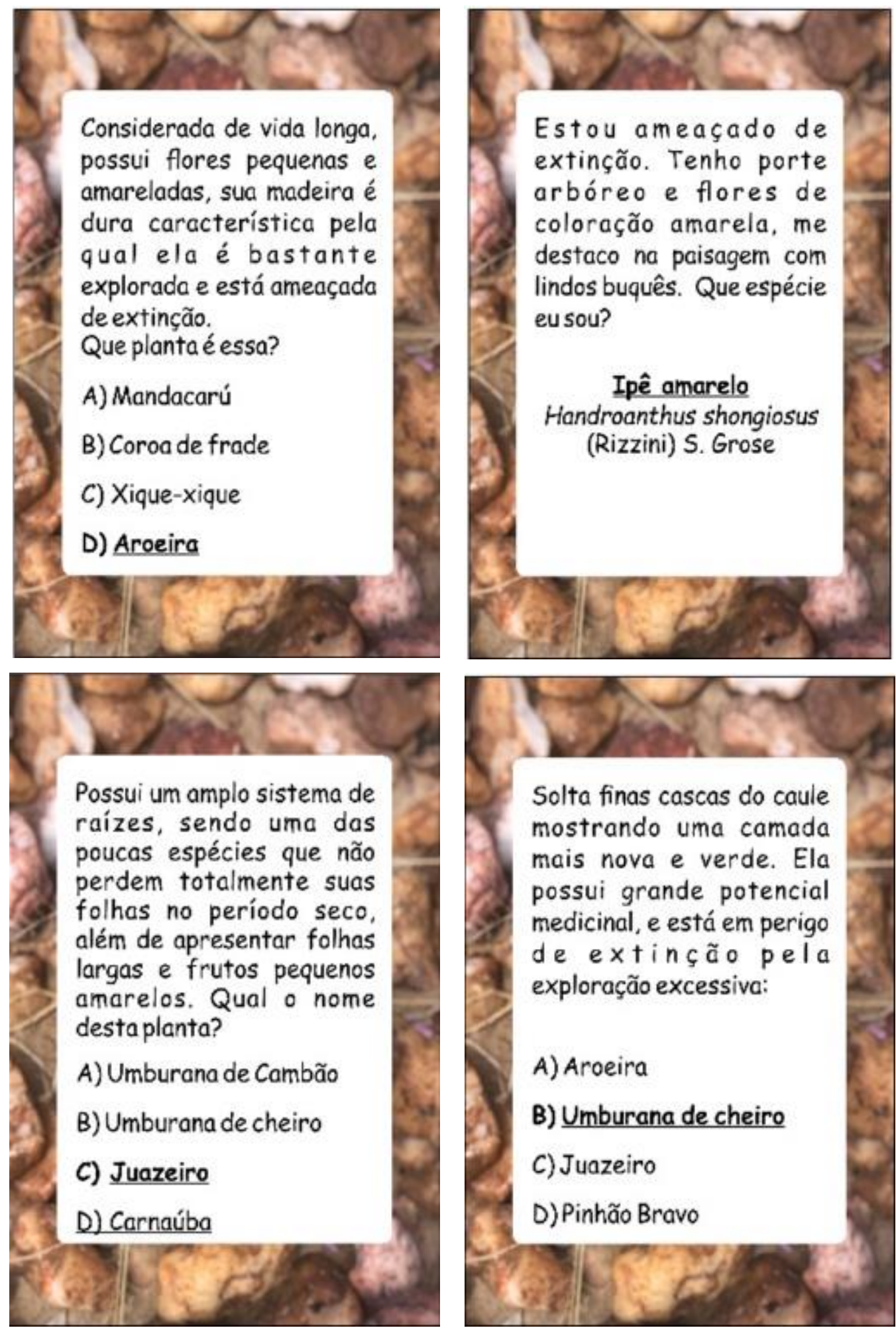

Figura 3: Cartas com perguntas do jogo Flora da Caatinga: conhecer para conservar (Continuação).

Fonte: autoria própria. 

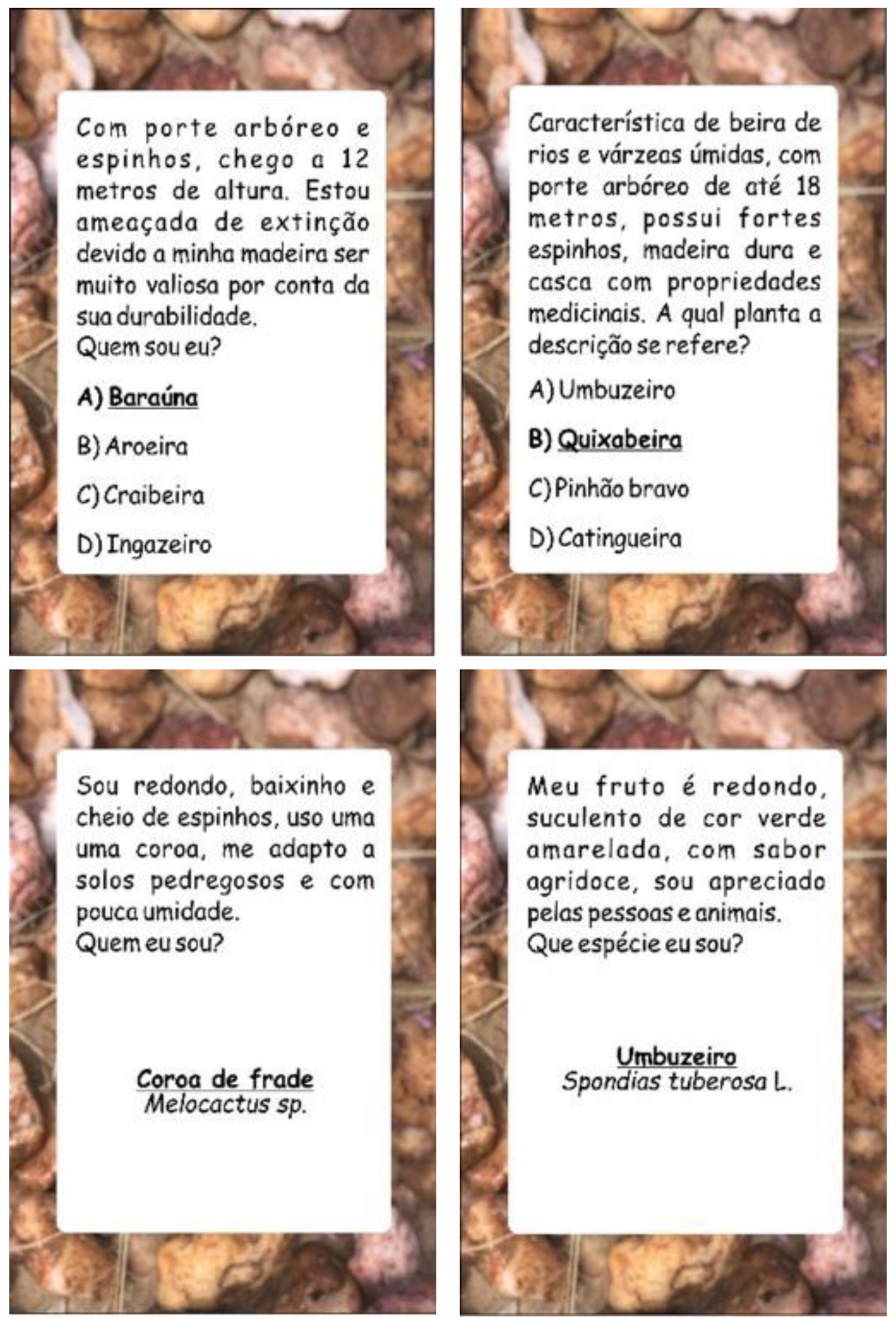

Figura 3: Cartas com perguntas do jogo Flora da Caatinga: conhecer para conservar (Continuação).

Fonte: autoria própria. 

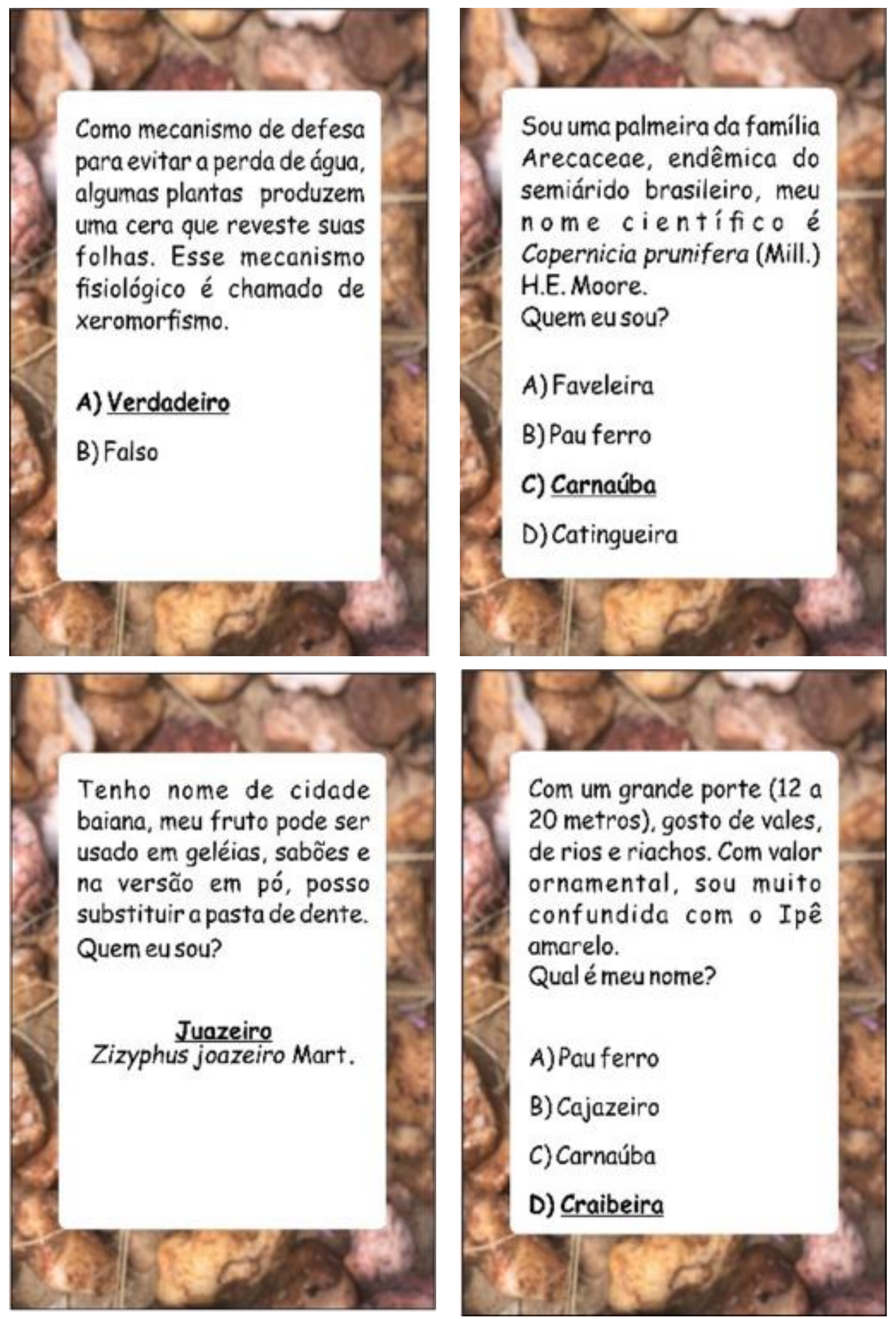

Figura 3: Cartas com perguntas do jogo Flora da Caatinga: conhecer para conservar (Continuação).

Fonte: autoria própria. 

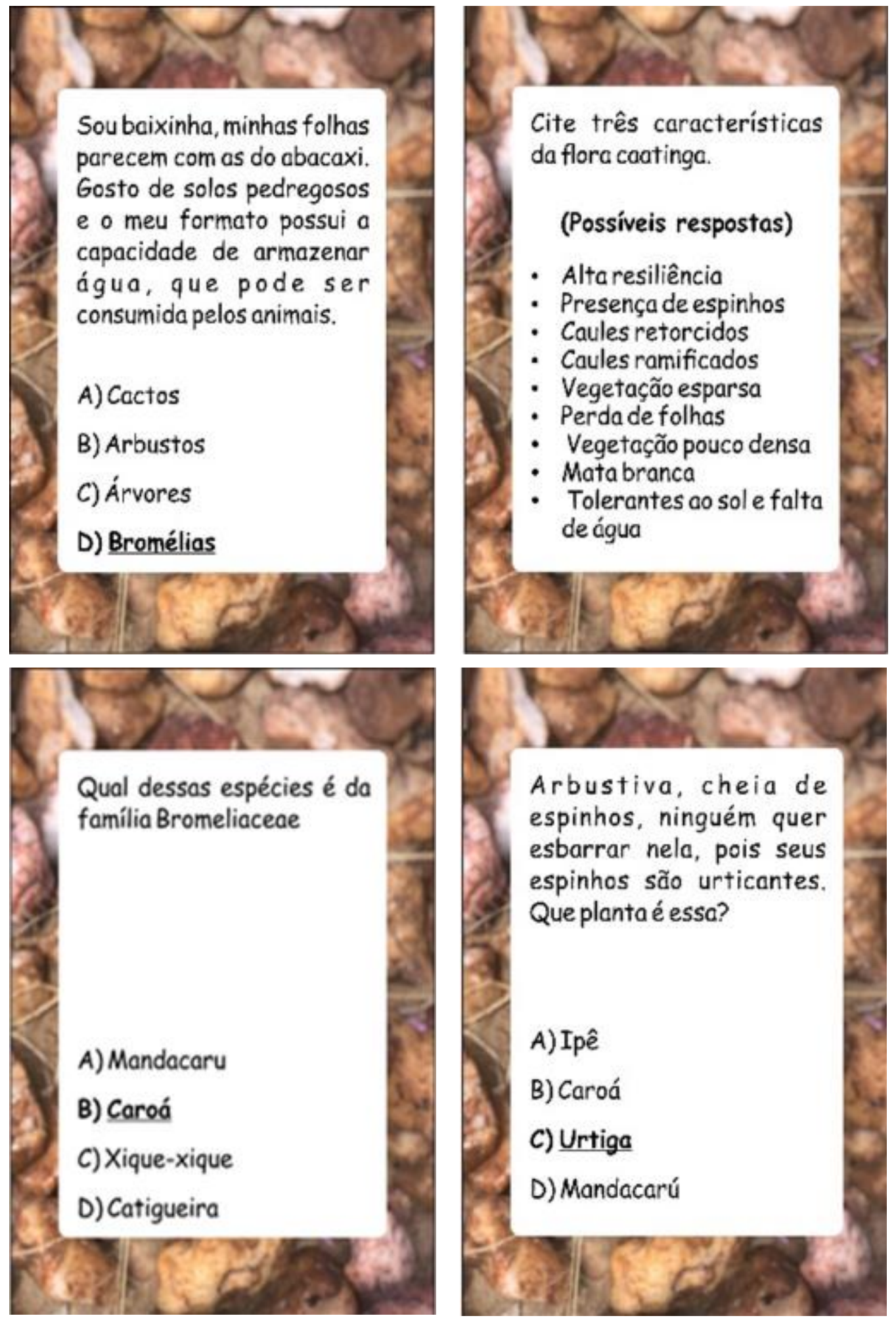

Figura 3: Cartas com perguntas do jogo Flora da Caatinga: conhecer para conservar (Continuação).

Fonte: autoria própria. 

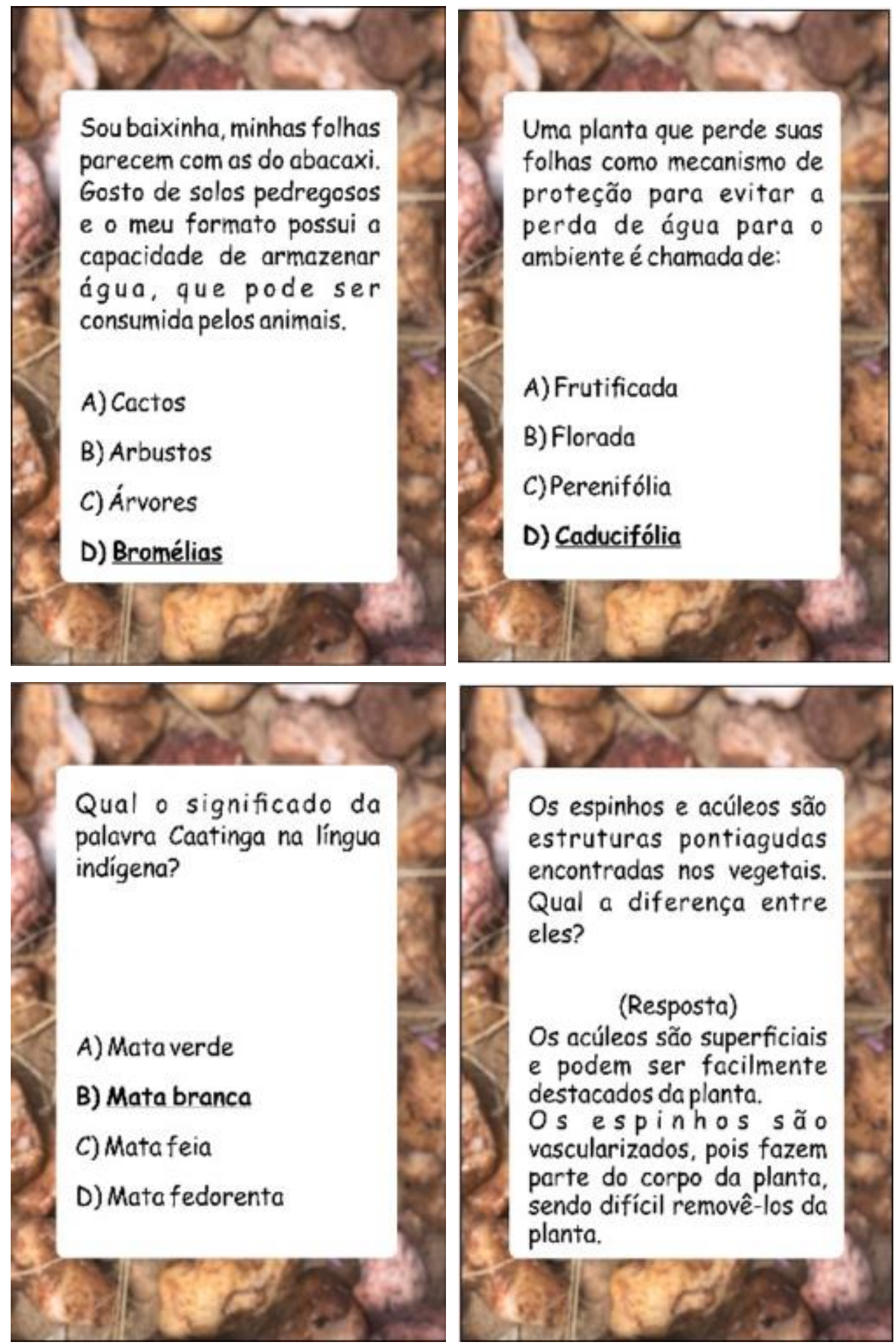

Figura 3: Cartas com perguntas do jogo Flora da Caatinga: conhecer para conservar (Continuação).

Fonte: autoria própria. 
Cada jogador será identificado como um dos ativistas ambientais, representados por pinos coloridos associados a uma carta com diversas informações sobre cada um deles (Figura 4). O vencedor será o (a) ativista que primeiro chegar ao final do tabuleiro, completando todo o caminho percorrido.
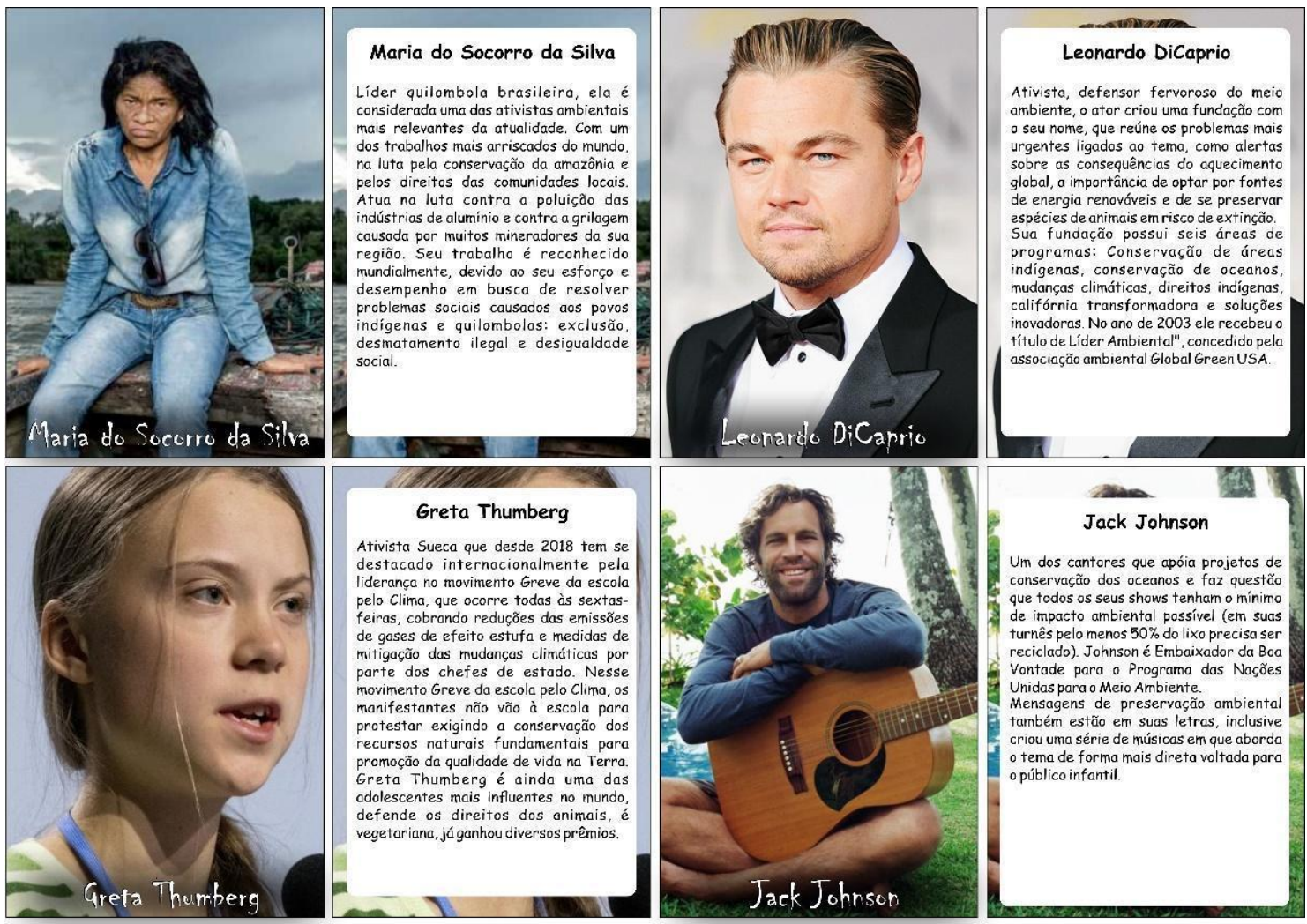

Figura 4: Cartas com ativistas ambientais do jogo Flora da Caatinga: conhecer para conservar. Fonte: autoria própria.

Como forma de auxiliar os jogadores com as perguntas, que irão surgir ao longo do caminho a ser percorrido, algumas casas contêm "bônus" (Figura 2), ficando a critério do jogador guardar essa carta para usá-las no momento mais oportuno. Esse bônus, apresentado no jogo através de uma lâmpada, poderá ser usado na forma de eliminação de uma alternativa em questões de múltiplas escolhas, ou pequenas dicas em outras questões como as charadas e perguntas abertas.

O jogo é composto por diversos elementos, que auxiliarão os jogadores (ativistas) a cumprirem a missão. Logo, existem "casas" que ajudarão no desempenho do jogo, denominadas "casas boas" (Tabela 2), como também possui obstáculos que poderão prejudicar os jogadores, denominadas "casas ruins" (Tabela 3), que tornarão o jogo mais competitivo. 
Tabela 2: Número da casa e descrição de premiação concedida aos jogadores.

\begin{tabular}{cl}
\hline $\begin{array}{c}\text { NÚMERO DA } \\
\text { CASA }\end{array}$ & \multicolumn{1}{c}{ DESCRIÇÃo DA PREMIAÇÃo } \\
\hline 8 & $\begin{array}{l}\text { Um grupo de brigadistas conseguiu conter um incêndio nesta região. Avance quatro } \\
\text { casas. }\end{array}$ \\
\hline 14 & $\begin{array}{l}\text { Apesar das condições climáticas, a Caatinga tem uma flora diversificada e resiliente. } \\
\text { Avance duas casas. }\end{array}$ \\
\hline 20 & $\begin{array}{l}\text { Dona Maria precisou realizar um desmatamento na sua propriedade para plantar } \\
\text { feijão. Para isso, ela solicitou ao órgão competente uma autorização de supressão } \\
\text { vegetal. Avance duas casas. }\end{array}$ \\
\hline 25 & Foi feita uma limpeza e retirado todo o lixo que havia neste local. Jogue novamente. \\
\hline 33 & $\begin{array}{l}\text { Essa área é alvo de recuperação ambiental. Avance duas casas. } \\
\text { de espécies nativas. Jogue novamente. }\end{array}$ \\
\hline 40 & $\begin{array}{l}\text { A flora da Caatinga é muito rica e oferece ao ser humano e aos animais uma } \\
\text { infinidade de alimentos e remédios. Avance duas casas. }\end{array}$ \\
\hline 67 & $\begin{array}{l}\text { Foi criado um plano de manejo sustentável para orientar a população sobre o } \\
\text { extrativismo vegetal de espécies nativas da Caatinga. Avance quatro casas. }\end{array}$ \\
\hline 66 & $\begin{array}{l}\text { Esse lugar é conservado e as práticas de manejo sustentável são aplicadas aqui. } \\
\text { Avance três casas. }\end{array}$ \\
\hline Você está bem próximo de uma Unidade de Conservação. Jogue novamente.
\end{tabular}

Fonte: Autoria própria.

Tabela 3: Número da casa no tabuleiro e descrição de penalidade aplicada aos participantes.

\begin{tabular}{|c|c|}
\hline $\begin{array}{l}\text { NÚMERO DA } \\
\text { CASA }\end{array}$ & DESCRIÇÃO DA PENALIDADE \\
\hline 5 & $\begin{array}{l}\text { Uma pessoa queimou os resíduos sólidos (lixo) da sua casa ao invés de dar a } \\
\text { destinação correta; o fogo se alastrou para a Caatinga, causando um grande } \\
\text { incêndio. Fique uma rodada sem jogar. }\end{array}$ \\
\hline 12 & $\begin{array}{l}\text { Um fazendeiro, ao comprar uma nova propriedade, desmatou toda a área sem } \\
\text { nenhuma autorização ambiental. Volte três casas. }\end{array}$ \\
\hline 17 & $\begin{array}{l}\text { Este lugar está altamente degradado, as espécies nativas foram retiradas para uso } \\
\text { como lenha e, agora, o solo encontra-se exposto. Volte duas casas. }\end{array}$ \\
\hline 24 & $\begin{array}{l}\text { O aumento do uso de agrotóxicos reduziu } 0 \text { número de polinizadores, } \\
\text { comprometendo a reprodução da flora da Caatinga. Volte duas casas. }\end{array}$ \\
\hline 29 & $\begin{array}{l}\text { Um grupo de pessoas visitou uma Unidade de Conservação de proteção integral e } \\
\text { pegou alguns espécimes de cactos para levar para suas casas. Volte três casas. }\end{array}$ \\
\hline 35 & $\begin{array}{l}\text { Esta região está em estágio avançado de desertificação. Fique uma rodada sem } \\
\text { jogar. }\end{array}$ \\
\hline 43 & $\begin{array}{l}\text { Um rebanho de caprinos comeu várias mudas, que foram plantadas para recuperar } \\
\text { essa área. Volte quatro casas. }\end{array}$ \\
\hline 52 & $\begin{array}{l}\text { O extrativismo do umbuzeiro está crescendo de forma desenfreada nesta região e } \\
\text { sem nenhuma prática de manejo sustentável. Volte duas casas. }\end{array}$ \\
\hline 64 & $\begin{array}{l}\text { Em uma visita de campo, um grupo de estudantes fez um piquenique e deixou todo } \\
\text { o lixo no local. Volte três casas. }\end{array}$ \\
\hline 70 & $\begin{array}{l}\text { Com a pressa em vencer, você esbarrou em uma urtiga (Cnidoscolus urens). Fique } \\
\text { uma rodada sem jogar. }\end{array}$ \\
\hline
\end{tabular}




\section{Regras do jogo flora da Caatinga: Conhecer para conservar}

A primeira etapa a se cumprir é a definição dos participantes. No caso da aplicação do jogo em uma turma com grande número de alunos, pode ser feita a divisão em grupos menores. Para que o jogo possa ser aplicado, é necessário até quatro alunos ou grupos, onde cada um será representado por um ativista ambiental. É imprescindível a presença de um mediador, que fará a leitura das cartas, a avaliação das respostas e auxiliará os participantes com as cartas bônus, ficando também responsável pelo cumprimento das regras durante a atividade.

O jogo deverá seguir um sentido único, que se inicia na casa "Partida". Cada ativista deverá iniciar jogando os dados para definir a ordem de largada, e a definição do jogador inicial da partida, o qual será estabelecido por aquele que obtiver o maior número nos dados. A ordem dos demais seguirá de forma decrescente de acordo com os números obtidos nos dados. No caso de empate, os dados deverão ser jogados novamente.

Definida a ordem de largada, cada aluno/grupo deve ler em voz alta as informações contidas nas cartas de cada ativista para que todo o grupo de participantes possa conhecer um pouco sobre cada personalidade. O jogo deve iniciar com o primeiro ativista respondendo à pergunta da carta. Para que possa jogar o dado e avançar na trilha, ele deverá acertar a pergunta que será feita. Caso erre, permanecerá na casa onde estava. O número dos dados definirá quantas casas ele (a) poderá avançar e, assim, passar para o próximo ativista.

No decorrer do tabuleiro, o jogador(es) poderá(ão) chegar a locais da trilha nomeados "casas surpresas", que contém possibilidades de retroceder ou avançar, a depender do tipo de informações contidas em cada casa. Caso seja a segunda vez que ele (s) estiver (em) jogando o dado na mesma rodada e reincidir em "casas surpresas", essa não terá validade. Também existe a possibilidade de o participante alcançar um ponto do jogo representado por uma lâmpada, contendo um bônus, que the confere o direito à aquisição de uma "carta bônus", que o ajudará a responder a uma das perguntas. Neste local, os participantes terão a possibilidade de usar a carta já na próxima rodada ou guardá-la para o momento mais oportuno.

Ganhará o jogo o ativista que primeiro alcançar a chegada. Caso o horário da aula não seja suficiente para algum aluno chegar ao final do jogo, vencerá aquele que atingir o local mais próximo à chegada final, lugar onde a vegetação da Caatinga estará conservada, e recebe como premiação um quebra-cabeça com imagem da Caatinga.

O jogo oferece o estímulo que favorece o desenvolvimento criativo dos alunos e permite ao professor ampliar suas técnicas de ensino, desenvolver capacidades profissionais para estimular a comunicação e expressão dos alunos, mostrando-Ihes uma nova maneira, lúdica, prazerosa e participativa de relacionar-se com o conteúdo escolar, propondo uma maior apropriação dos conhecimentos envolvidos (BRASIL, 2002). Além disso, os jogos promovem o 
desenvolvimento cognitivo na criança, construindo habilidades e competências, como atenção, o respeito às regras, interação social e cooperação, propondo também adaptação do sujeito ao meio em que vive (PIAGET, 1994).

A literatura aborda os jogos didáticos como instrumentos eficientes para promoção de aprendizagem acerca de diversas temáticas através da atividade lúdica (MOURA; GOMES; RIBEIRO, 2020; MIRANDA; GONZAGA; COSTA, 2016; GONZAGA et al. 2017; ROSÁRIO, 2019).

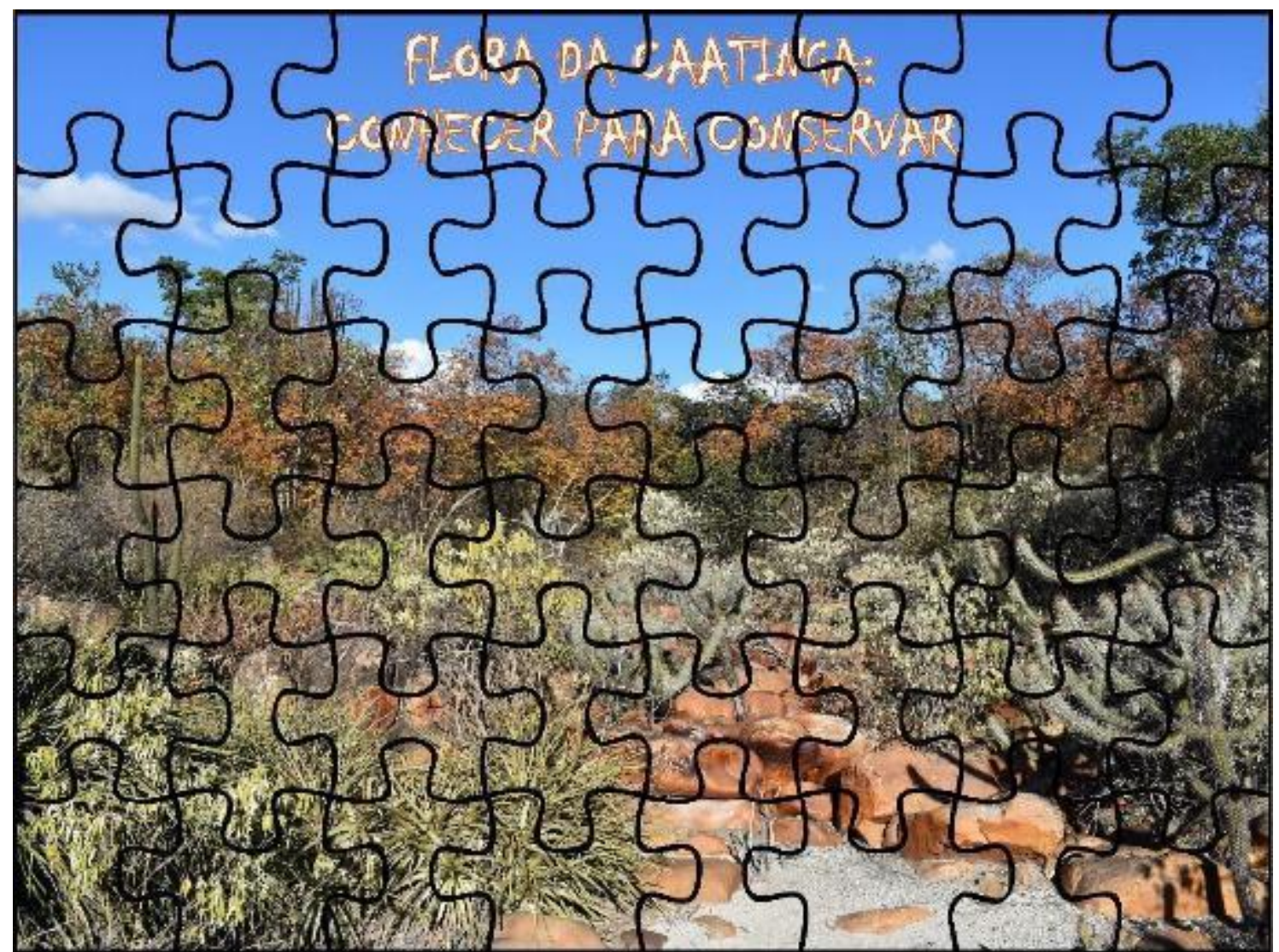

Figura 5: Quebra-cabeça, prêmio do jogo Flora da Caatinga: Conhecer para conservar.

Fonte: Autoria própria.

Segundo Silva (2016), o jogo é um importante instrumento para promover EA na escola por combinar ludicidade a aspectos cognitivos, permitindo ao aluno construir seu próprio conhecimento, além de promover a sensibilização e posicionamento diante de problemas ambientais, estimulando a mudança de atitudes e a construção de valores ambientalmente corretos. $O$ autor supracitado elaborou um jogo de tabuleiro chamado de "Trilha da água: $O$ meio ambiente em foco", contendo casas a serem avançadas à medida que as perguntas fossem respondidas pelos alunos. Os resultados apresentados por Silva (2016) revelaram que o jogo de tabuleiro criou um ambiente divertido de aprendizagem, no qual foram abordadas temáticas ambientais importantes, como poluição do ar, água e solo, desmatamentos, queimadas, impactos das atividades antrópicas sobre o meio ambiente, promovendo conscientização ambiental.

revista brasileira educação ambiental 


\section{Conclusões}

A proposta do jogo didático Flora da Caatinga: Conhecer para conservar sinaliza um esforço no sentido de auxiliar os alunos tanto na compreensão da sua relação com o espaço em que vivem, quanto na relevância de se adotarem posturas mais assertivas em relação ao meio ambiente. Além disso, auxilia professores pois é uma ferramenta desenvolvida e disponibilizada para abordar a flora da Caatinga. Essa proposta contribui também para o fortalecimento da EA, uma vez que propicia a reflexão e conscientização ambiental dos estudantes enquanto promove aprendizagem acerca do meio ambiente e de suas problemáticas.

Além disso, é importante ressaltar que o âmbito escolar serve como um canal de desenvolvimento de saberes e levantamento de debates no que diz respeito à Caatinga, buscando formar educandos reflexivos, conscientes, críticos e ativos. O jogo didático desenvolvido se insere nesse cenário como recurso para prática da EA no Ensino Fundamental, à medida que estimula a reflexão dos participantes do jogo sobre os impactos ocasionados pela ação antrópica na Caatinga, assim como, demonstra e incentiva a prática de ações de conservação.

\section{Agradecimentos}

Ao Programa de Pós-graduação em Ciência e Tecnologia Ambiental (PPGCTA) da Universidade de Pernambuco Campus Petrolina.

À Coordenação de Aperfeiçoamento de Pessoal de Nível Superior (CAPES), Brasil - Código de Financiamento 001.

À Fundação de Amparo a Ciência e Tecnologia do Estado de Pernambuco (FACEPE) pela concessão de bolsas e financiamento do projeto "Aprendendo sobre o valor da biodiversidade da Caatinga e seus serviços ecossistêmicos no ensino escolar" (FACEPE APQ - 0177-2.05/18).

\section{Referências}

ANDRADE-LIMA, D. The caatinga dominium. Rev. Bras. Bot. v. 4, p. 149-153, 1981.

ALVES, A.T.J.; HENDGES, C.R.; SANDER, I.T.; PAZ, D. Reciclagem: educar para conscientizar. Anais do II Seminário Interinstitucional de Ensino, Pesquisa e Extensão. UNICRUZ, 2012.

ARDOIN, N.M.; BOWERS, A.W. Early childhood environmental education: A systematic review of the research literature. Educational Research Review, 31, 100353, 2020. https://doi.org/10.1016/j.edurev.2020.100353

BAKKE, O.A. et al. Produção e utilização da forragem de espécies lenhosas da Caatinga. In: GARIGLIO, M. A. et al. (Org.). Uso Sustentável e Conservação dos Recursos Florestais da Caatinga. 2 ed. Brasília: Ministério do Meio Ambiente, 2010. 
BRASIL. Parâmetros Curriculares Nacionais: Introdução aos Parâmetros Curriculares Nacionais. Secretaria de Educação Fundamental. - Brasília: MEC/SEF, v. 1, p. 126, 1998.

BRASIL. Lei no 9.795, de 27 de abril de 1999. Dispõe sobre a educação ambiental, institui a Política Nacional de Educação Ambiental e dá outras providências. Brasília, DF: Presidência da República, 1999. Disponível em: <http://www.planalto.gov.br/ccivil 03/leis/19795.htm>. Acesso em: 20 out. 2020.

BRASIL. Secretaria de Educação Média e Tecnológica. PCN+ Ensino Médio: orientações educacionais complementares aos Parâmetros Curriculares Nacionais. Ciências da Natureza, Matemática e suas Tecnologias. Brasília: MEC/SEMTEC, 2002.

BRASIL. Base Nacional Comum - BNCC. Brasília: MEC, 2018. Disponível em: $<$ https://doi.org/10.1017/CBO9781107415324.004>

CORREIA, R.C.; KILL, L.H.P.; MOURA, M.S.B.; CUNHA, T.J.F.; JESUS JÚNIOR, L.A.; ARAÚJO, J.L.P. A região semiárida Brasileira. In: VOLTOLINI, T.V. (Org.). Produção de caprinos e ovinos no Semiárido. Petrolina: Embrapa Semiárido, 2011.

CAGLE, N.L. Changes in experiences with nature through the lives of environmentally committed university faculty. Environmental Education Research, v. 24, n. 6, p. 889-898, 2018.

CHAWLA, L. Childhood experiences associated with care for the natural world: A theoretical framework for empirical results. Children, Youth, and Environments, v. 17, n. 4, p. 144-170, 2007.

CHAWLA, L. Growing up green: becoming an agent of care for the natural world. Journal of Developmental Processes v. 4, n. 1, p. 6-23, 2009.

FERNANDES, M.F.; CARDOSO, D.; QUEIROZ, L.P. An updated plant checklist of the Brazilian Caatinga seasonally dry forests and woodlands reveals high species richness and endemism. Journal of Arid Environments, v. 174, p. 104079, 2020.

FERNANDES, M.F.; QUEIROZ, L.P. Vegetação e flora da Caatinga. Ciência e Cultura, v. 70, n. 4, p. 51-56, 2018.

FORTUNA, T.R. Jogo em aula: recurso que permite repensar as relações ensino-aprendizagem. Revista do Professor, v. 19, n. 75, p. 15-9, 2003.

GARCIA, M.A.; ZANETI, I.C.B.B.; YONAMINE, S.M.; SILVERIO, A.P.; CERQUEIRA, E.N.G.M.; SILVA, M.G.L. Duas décadas da PNEA: Avanços e Retrocessos no Brasil. Revista Brasileira de Educação Ambiental (RevBEA), v. 15 , n. 5, p. 250-270, 2020.

GARIGLIO, M.A. et al. Uso sustentável e conservação dos recursos florestais da Caatinga. Brasília: Serviço Florestal Brasileiro, 2010. 
GIULIETTI, A.M.; CONCEIÇÃO, A.; QUEIROZ, L.P. Diversidade e caracterização das Fanerógamas do semi-árido Brasileiro: Bignoniaceae. Instituto do Milênio do Semiárido. v. 1, 2006.

GIULIETTI, A.M. et al. Diagnóstico da vegetação nativa do bioma Caatinga. Mycopathologia et Mycologia Applicata, v. 18, n. 1-2, p. 63-83, 2002.

GONZAGA, G.R.; COSTA, R.C. Produção e avaliação do jogo didático "tapa zoo" como ferramenta para o estudo de zoologia por alunos do ensino fundamental regular. Holos, v. 4, p. 383, 2016.

GONZAGA, G. et al. Jogos didáticos para o ensino de Ciências. Revista Educação Pública, v. 17, n. 7, p. 1-12, 2017.

GUSMÃO, L.F.P.; QUEIROZ, L.P.; QUIJANO, F.R.B.; JUNCÁ, F.A.; OLIVEIRA, R.P; BASEIA. I.G. Caatinga: diversidade na adversidade do Semiárido Brasileiro. In: PEIXOTO, A.L.; LUZ, J.R.P.; BRITO, M.A. (Org.). Conhecendo a biodiversidade. Brasília: MCTIC, CNPq, PPBio, 2016.

JAMES, J.J.; BIXLER, R.D.; VADALA, C.E. From play in nature, to recreation then vocation: a developmental model for natural history-oriented environmental professionals. Children, Youth, and Environments, v. 20, n. 1, p.231-256, 2010.

LEAL FILHO, W.; MIFSUD, M.; PACE, P. Handbook of lifelong learning for sustainable development. World Sustainability Series. Berlin: Springer International, 2018.

LEAL, I.R. et al. Mudando o curso da conservação da biodiversidade na Caatinga do Nordeste do Brasil. Megadiversidade, v. 1, 2005.

LUCCHESE, N.R.; ALVES, G.L. A Educação Ambiental nas escolas estaduais de ensino médio em Campo Grande, MS. Revista HISTEDBR, n. 51, p. 303322, 2013.

MACHADO, M.G.; ABÍLIO, F.J.P. Educação Ambiental no bioma Caatinga: a utilização de modalidades didáticas inovacionais na realização de vivências eco pedagógicas. XIII Congresso internacional de tecnologia na educação, 2015.

MEDINA, N.M. Breve histórico da Educação Ambiental, 2008. Disponível em:

http://www.cursoecologia.ufba.br/Arquivos/Educacao Ambiental/Breve\%20hist \%C3\%B3rico\%20da\%20educa\%C3\%A7\%C3\%A30\%20ambiental.doc

MENEZES, I.S. Uma abordagem lúdica no ensino de botânica: análise dos jogos didáticos na construção do conhecimento. (Monografia - Curso de Licenciatura em Ciências Biológicas). Itapetinga- BA: UESB. 2012

MIRANDA, J.C.; MILES, L.; NEWTON, A. C.; DEFRIES, R. S.; RAVILIOUS, C.; MAY, I.; BLYTH, S.; KAPOS, V.; GORDON, J. E. A global overview of the conservation status of tropical dry forests. J. Biogeogr. v. 33, p. 491-505, 2006. 
MORO, M.F.; ARAÚJO, F.S.; RODAL, M.J.N.; MARTINS, F.R. Síntese dos estudos florísticos e fitossociológicos realizados no semiárido brasileiro. In: EISENLOHR, P.V.; FELFILI, J.M.; MELO, M.M.R.F.; ANDRADE, L.A.; MEIRANETO, J.A.A. (Eds.). Fitossociologia no Brasil: métodos e estudos de caso. Vol. II. Viçosa: Editora da Universidade Federal de Viçosa, 2015.

MORO, M.F.; LUGHADHA, E.N.; FILER, D.L.; ARAÚJO, F. S. D.; MARTINS, F. R. A catalogue of the vascular plants of the Caatinga Phytogeographical Domain: a synthesis of floristic and phytosociological surveys. Phytotaxa, v. 160, p. 1-118. 2014.

MOURA, M.A.R.; GOMES, K.D.M.; RIBEIRO, E.M.S. Construção e testagem de um jogo didático com foco nas aves da caatinga. VI Congresso Nacional de educação, 2020.

ONU. Organization United Nations. Take Action for the Sustainable Development Goals. Disponível em: <https://www.un.org/sustainabledevelopment/sustainable-development-goals/> Acesso em:12/10/2020.

QUEIROZ, L.P.; CARDOSO, D.; FERNANDES, M.; MORO, M. Diversity and evolution of flowering plants of the Caatinga domain. In: SILVA, J.C.; LEAL, I.; TABARELLI, M. (Eds.). Caatinga: the largest tropical dry forest region in South America. Cham: Springer, 2017.

REIS, W.F.; MARQUES, G.S. Gestão de resíduos sólidos (RS) e mudanças climáticas: evolução do índice de intensidade de carbono de RS para o Brasil 2030. REDE - Revista Eletrônica do PRODEMA, v. 12, n. 03, p. 18-29, 2018.

ROSA, C.D.; PROFICE, C.C.; COLLADO, S. Nature experiences and adults' self-reported pro-environmental behaviors: the role of connectedness to nature and childhood nature experiences. Frontiers in Psychology, v. 26, 2018. Disponível em: https://doi.org/10.3389/fpsyg.2018.01055

ROSÁRIO, C.S. Educação Ambiental e atividades lúdicas para a identificação da importância das distintas formas de vida (fauna e flora). Revista Brasileira de Educação Ambiental (RevBEA), v. 14, n. 3, p. 155-168, 2019.

SAMUELSSON, I.; KAGA, Y. The contribution of early childhood education to a sustainable society, UNESCO, 2008. Disponível em: <https://unesdoc.unesco.org/ark:/48223/pf0000159355>.

SANTOS, J.C. et al. Caatinga: the scientific negligence experienced by a dry tropical forest. Tropical Conservation Science, v. 4, n. 3, p. 276-286, 2011.

SENA, L.M.M. Conheça e conserve a Caatinga: o bioma Caatinga. Vol 1. Fortaleza: Associação Caatinga. 2011.

SILVA, A.F. O jogo didático como instrumento para séries finais do ensino fundamental: proposta para trabalhar os temas ambientes e diversidade. Revista Brasileira de Educação Ambiental (RevBEA), v. 11, n. 5, p. 167183, 2016. 
SILVA, C.G. et al. Levantamento etnobotânico de plantas medicinais em área de Caatinga na comunidade do Sítio Nazaré, município de Milagres, Ceará, Brasil. Revista Brasileira de Plantas Medicinais, v. 17, n. 1, p. 133-142, 2015.

TABARELLI, M. et al. Caatinga: legado, trajetória e desafios rumo à sustentabilidade. Ciência e Cultura, v. 70, n. 4 p. 25-29, 2018.

TRIGUEIRO, P. Especialistas debatem educação no semiárido. Folha de Pernambuco, Pernambuco, jun. 2017. Disponível em: $<$ http://folhape.com.br/noticias/noticias/cotidiano/2017/06/13/NWS,30941,70,44 9,NOTICIAS,2190-ESPECIALISTAS-DEBATEM-EDUCACAOSEMIARIDO.aspx>. Acesso em: 10/10/2020.

UNESCO. Intergovernmental conference on environmental education: Final report. Paris, France, 1978.

WILSON, R.A. Environmental education programs for preschool children. The Journal of Environmental Education, v. 27, n. 4, p. 28-33, 1996.

WELLS, N.M.; LEKIES, K.S. Nature and the life course: pathways from childhood nature experiences to adult environmentalism. Children, Youth, and Environments, v. 16, n. 1, p. 1-24, 2006.

WWF. World Wildlife Fund. Tackling threats that impact the Earth. Disponivel em: https://www.worldwildlife.org/threats> Acesso em: 12/10/2020

ZUPELARI, M.F.Z.; WICK, M.A.L. A incerteza do futuro e a questão ambiental na contemporaneidade. Revista Subjetividades, v.15, n.1, 2015. 